\title{
Process Improvement in Manual Lapping Process
}

\section{Pneumatic Automated Lapping System}

\author{
P. Martin Premkumar, J. Michel Ditto \\ Department of Mechanical Engineering, \\ Loyola-ICAM College of Engineering and Technology \\ (LICET), Chennai, India
}

\author{
M. Karthi \\ Assistant Professor, \\ Department of Mechanical Engineering, \\ Loyola-ICAM College of Engineering and Technology \\ (LICET), Chennai, India
}

\begin{abstract}
Industry 4.0 aims at automation of manufacturing processes in order to facilitate high production rate of good quality products. We present here an automatic lapping system which was designed for achieving surface flatness and air tight seal between the Flapper Valve and Ram cylinder cover, that builds up pressure in the clamping unit of an injection moulding machine. This automatic lapping system was designed in-order to reduce human work load and to lessen the present time consumption in manual lapping process. In-order to build an automatic lapping system, an oscillating mechanism was designed to limit the rotation of the Flapper Valve over the Ram cylinder cover to an angle stated by the end user. A pneumatic source was chosen based on the availability to actuate the oscillating mechanism. We hope that this proposed design will increase the efficacy of lapping process when compared with previously used manual lapping method.
\end{abstract}

Keywords - Surface flatness; human work load; time consumption; manual lapping method; pneumatic source; oscillating mechanism .

\section{INTRODUCTION}

An Injection moulding machine consists of an injection unit, mould unit and a clamping unit. Clamping unit is used to keep the mould shut against the forces developed, when the injection pressure pushes plastic into the closed mould. Therefore the amount of clamping force must be at least equal to the amount of injection force. The clamping unit is actuated by an hydraulic cylinder, which is directly connected to the hydraulic pump. The clamping unit consists of a suction flange cover assembly, which is composed of flapper valve and ram cylinder cover. When the oil enters the ram cylinder cover, it pushes the ram forward which in turn moves the moving plate and keeps the mould shut against the forces developed by the injection unit. The required clamping force which has to be at least equal to the injection pressure should be given by the clamping unit throughout the dwell time. At the end of dwell time the oil is released from the ram cylinder cover and the mould is opened. Since a steady clamping force has to be given by the clamping unit against the injection force, the oil which is taken in between the flapper valve and suction flange cover assembly should not be released throughout the dwell time. Hence it is very important that, there should be a good surface finish between the flapper valve and ram cylinder cover.
At present, in-order to achieve a good surface finish between the two sub-assemblies, a manual lapping approach was followed.

\section{METHODOLOGY}

\section{A. Problem definition}

Manual lapping process, is done between the flapper valve and ram cylinder cover using a rotator. It takes up-to 200 manual rotations of flapper valve over the ram cylinder cover by applying man power. It takes almost 2 days to complete the lapping process between all the available assemblies of flapper valve and ram cylinder cover.

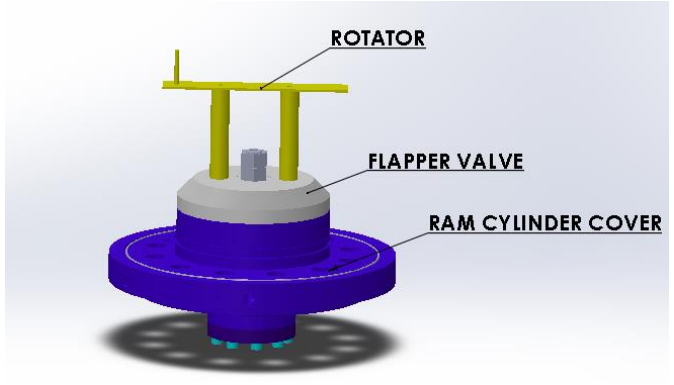

Fig.1. Manual lapping process

\section{B. Pneumatic Automated Lapping System}

Since the above problem defines the human work load and time consumption involved in the manual lapping process, there is a need created to automate this lapping process.

In-order to limit the movement of rotation to a required oscillating angle of 90 degrees by the end user, suitable mechanism was selected from the following technical analysis in table I.

An oscillating cylinder mechanism was selected for the lapping system from technical analysis. Pneumatic source is an easily available source for the end user to actuate this system. Hence the oscillating cylinder mechanism was designed in such a way that it is actuated by the available pneumatic source of 5 bar pressure 
TABLE I. TECHNICAL ANALYSIS

\begin{tabular}{|l|l|l|l|}
\hline S.NO & SOLUTIONS & MERITS & DEMERITS \\
\hline 1. & $\begin{array}{l}\text { Single slider } \\
\text { crank } \\
\text { mechanism }\end{array}$ & $\begin{array}{l}\text { Simple in } \\
\text { construction. }\end{array}$ & $\begin{array}{l}\text { i) Difficult to achieve the } \\
\text { required angle needed by } \\
\text { the end user }\end{array}$ \\
\hline 2. & $\begin{array}{l}\text { Cam and } \\
\text { follower } \\
\text { mechanism }\end{array}$ & $\begin{array}{l}\text { Various } \\
\text { angles and } \\
\text { timing can } \\
\text { be achieved. }\end{array}$ & $\begin{array}{l}\text { ii) Construction is } \\
\text { complex and requires } \\
\text { more components. }\end{array}$ \\
\hline 3. & $\begin{array}{l}\text { Crank and } \\
\text { slotted lever } \\
\text { quick return } \\
\text { mechanism }\end{array}$ & $\begin{array}{l}\text { Work done } \\
\text { is less. }\end{array}$ & $\begin{array}{l}\text { iii) Slot may not withstand } \\
\text { heavy loads. }\end{array}$ \\
\hline & $\begin{array}{l}\text { Oscillating } \\
\text { cylinder } \\
\text { mechanism }\end{array}$ & $\begin{array}{l}\text { Simple in } \\
\text { construction } \\
\text { and use less } \\
\text { components. }\end{array}$ & $\begin{array}{l}\text { iv) Accurate angles cannot } \\
\text { be achieved. }\end{array}$ \\
\hline
\end{tabular}

\section{Analysis on pneumatic cylinder}

Since it was earlier stated that the system should make the flapper valve rotate to an angle of 90 degrees, the required stroke length has been found to achieve the stated condition. For the standard pneumatic cylinders available in the market, the stroke length varies according to the cylinder length. Table II. gives the database about the standard cylinder lengths and its available stroke lengths.

TABLE.II STANDARD CYLINDER LENGTHS AND ITS CORRESPONDING STROKE LENGTHS

\begin{tabular}{|l|l|}
\hline $\begin{array}{l}\text { STANDARD CYLINDER LENGHTS } \\
(\mathbf{m m})\end{array}$ & $\begin{array}{l}\text { STROKE LENGTHS } \\
(\mathbf{m m})\end{array}$ \\
\hline 240 & 50 \\
\hline 290 & 100 \\
\hline 314 & 125 \\
\hline
\end{tabular}

For the mentioned standard cylinder lengths, the actually required stroke lengths were calculated theoretically using Auto Cad software.

\section{Iteration 1 (for the cylinder length of $240 \mathrm{~mm}$ )}

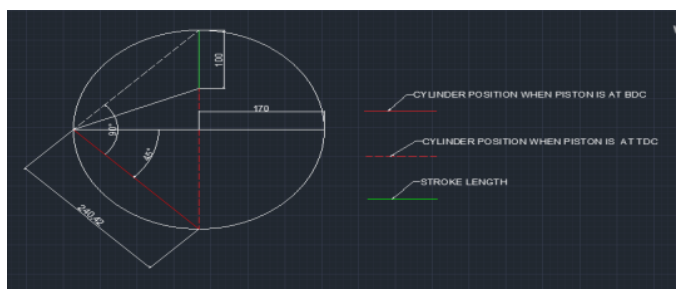

Fig.2. Stroke length claculation for cylinder model 1

\section{Iteration 2 (for the cylinder length of $290 \mathrm{~mm}$ )}

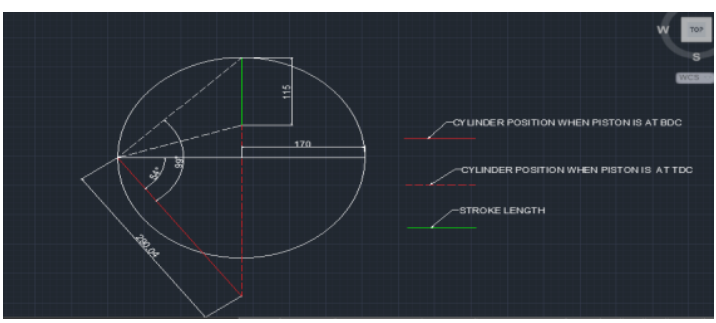

Fig.3. Stroke length claculation for cylinder model 2

Inference - The actual stroke length required is $115 \mathrm{~mm}$

Actual stroke length < Available standard stroke length.

Iteration 3 (for the cylinder length of $314 \mathrm{~mm}$ )

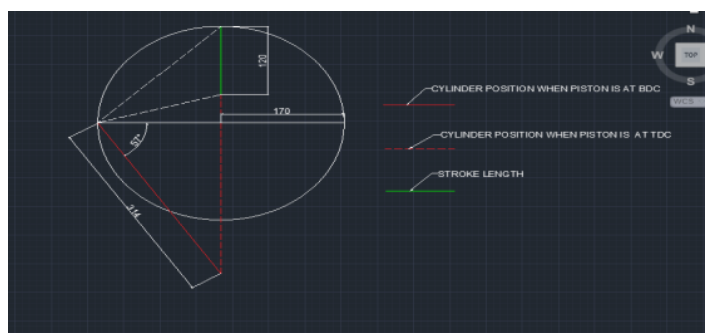

Fig.4. Stroke length claculation for cylinder model 3

Inference - The actual stroke length required is $120 \mathrm{~mm}$.

Actual stroke length < Available standard stroke length.

From the following iterations cylinder of length 314 was selected since the variation is small between actual stroke length and standard stroke length.

\section{Technical analysis on pneumatic circuit}

In-order to automate the designed oscillating cylinder mechanism, we technically analysed various pneumatic direction control valves to actuate the pneumatic cylinder

From Table III. Mechanically operated toggle switch was selected to automate the double acting pneumatic cylinder.

Inference - The actual stroke length required is $100 \mathrm{~mm}$

Actual stroke length < Available standard stroke length. 
TABLE.III. TECHNICAL ANALYSIS ON PNEUMATIC SWITCHES

\begin{tabular}{|c|c|c|c|}
\hline S.NO & SOLUTIONS & MERITS & DEMERITS \\
\hline 1 & $\begin{array}{l}\text { Standard } \\
\text { solenoid valve }\end{array}$ & $\begin{array}{l}\text { i) It is versatile } \\
\text { and adaptable } \\
\text { ii) It has fast } \\
\text { response time }\end{array}$ & $\begin{array}{l}\text { i) Availability of electrical } \\
\text { source is mandatory } \\
\text { ii) The valve can partly } \\
\text { close if the magnetic field } \\
\text { isn't setup correctly } \\
\text { It is costlier }\end{array}$ \\
\hline 2. & $\begin{array}{l}\text { Mechanically } \\
\text { operated } \\
\text { direction } \\
\text { control } \\
\text { valves(button } \\
\text { switches) } \\
\end{array}$ & $\begin{array}{l}\text { i) It is cost } \\
\text { efficient } \\
\text { ii) It does not } \\
\text { require } \\
\text { electrical } \\
\text { source }\end{array}$ & $\begin{array}{l}\text { i) It cannot automate the } \\
\text { mechanism } \\
\text { ii) It does not have fast } \\
\text { response time }\end{array}$ \\
\hline 3 & $\begin{array}{l}\text { Mechanically } \\
\text { operated } \\
\text { direction } \\
\text { control } \\
\text { valves(Toggle } \\
\text { switches) }\end{array}$ & $\begin{array}{l}\text { i) It can } \\
\text { automate the } \\
\text { mechanism } \\
\text { ii) It is cost } \\
\text { efficient } \\
\text { ii) It is highly } \\
\text { durable } \\
\text { iii) It does not } \\
\text { require } \\
\text { electrical } \\
\text { source. }\end{array}$ & $\begin{array}{l}\text { i) It does not respond as } \\
\text { fast as a solenoid valve }\end{array}$ \\
\hline
\end{tabular}

\section{E. Technical specification:}

\section{Force required to oscillate $: 30 \mathrm{~kg}=294.3 \mathrm{~N}$ \\ Angle of oscillation $: 90^{\circ}$ \\ Pressure \\ Diameter of piston \\ Stroke length \\ Type of cylinder \\ $: 5 \mathrm{bar}=0.5 \mathrm{~N} / \mathrm{mm}^{2}$ \\ $: 32 \mathrm{~mm}$ \\ $: 125 \mathrm{~mm}$ \\ : Bi-directional pneumatic cylinder \\ Type of sensor \\ : Proximity sensor \\ Type of directional valve $: 3 / 2$ toggle valve resettable \\ Switches, 5/2 double pilot valves}

FRL unit is to adjust the speed and automate the pneumatic system

\section{F. Design of pneumatic circuits}

After considering the mechanically operated toggle switches from the technical analysis to actuate the pneumatic system, we designed a pneumatic circuit using automation studio software, which builds a pneumatic system.

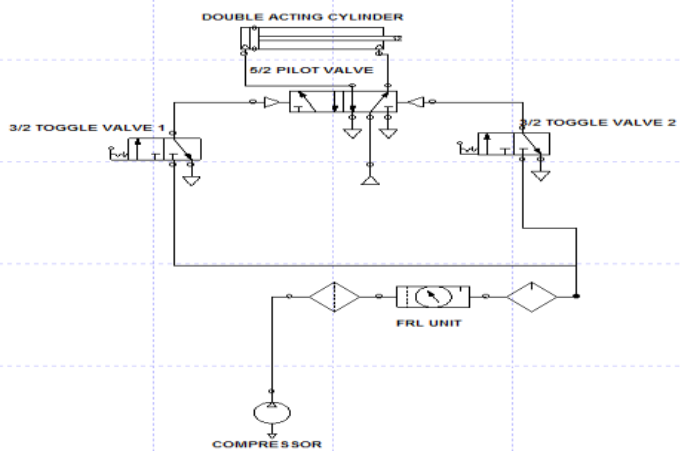

Fig.5. Pneumatic circuit
Figure 5 explains the pneumatic circuit which automates the system. Air from the compressor flow through the Filter Regulator Lubricator (FRL). From the FRL, two tubes are connected to the input valves of $5 / 2$ double external pilot operated valves and two tubes are connected to input valve of two $3 / 2$ toggle switches. The output of $5 / 2$ pilot valve is connected to two positions of double acting pneumatic cylinder. The output of $3 / 2$ toggle valve is connected to the directional control of $5 / 2$ pilot valve. When the air from the compressor passes to the FRL, it removes the dust from the compressed air. After passing through the FRL, the air is split to various valves through the tubes connected from it. All the valves is normally closed. When the rotator hits the $3 / 2$ toggle valve at the $0^{0}$ position, the toggle 1 is activated and allows the air to pass to the directional control of pilot valve, which allows the air from the input valve of pilot valve to the double acting pneumatic cylinder in BDC (Bottom Dead Centre) position. This process will make the piston to move from BDC to TDC and achieve a rotation of $90^{\circ}$. Once the rotator reaches the $90^{\circ}$ position, it hits another $3 / 2$ toggle valve, the toggle 2 is activated and allows the air to pass to the directional control of pilot valve, which allows the air from the input valve of pilot valve to the double acting pneumatic cylinder in TDC(Top Dead Centre) position. This process will make the piston to move from TDC to BDC and achieve a rotation of $90^{\circ}$. By this operation, oscillation of $90^{\circ}$ is achieved.

\section{G. Components required for the system}

\section{Assemblies:}

i) Fixture

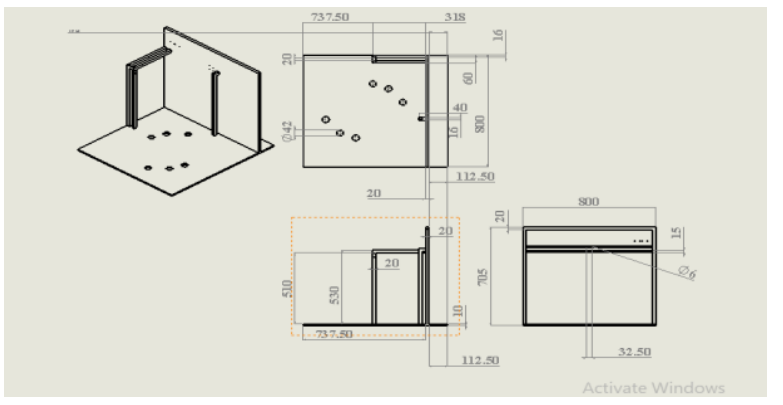

Fig.6. Fixture design

It was designed in order to fix the suction flange cover assembly in a proper position. Other assemblies such as pneumatic cylinder, toggle switches are fixed to the fixture in proper location with the help of other sub-assemblies such as movable flange, fixed flange and I-shaped structure.

ii) Double acting pneumatic cylinder

It provides an oscillating mechanism to the flapper valve, by the repeated forward and return stroke by the piston. 


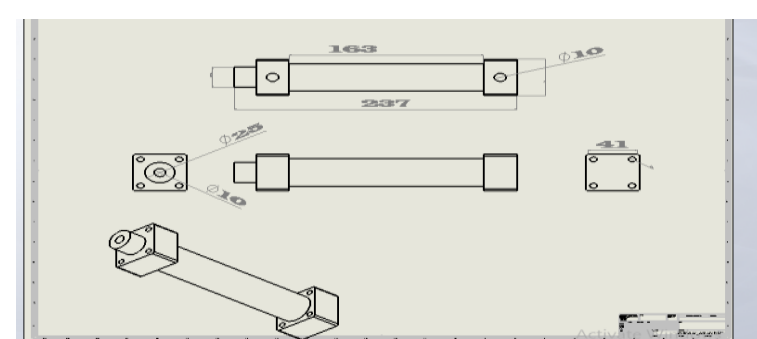

Fig.7. Double acting Pneumatic cylinder design

iii) Filter Lubricator Regulator Unit (FRL Unit)

Air from a compressor unit is allowed to pass through the FRL unit . The FRL unit splits the air between the two ports of the double acting cylinder.

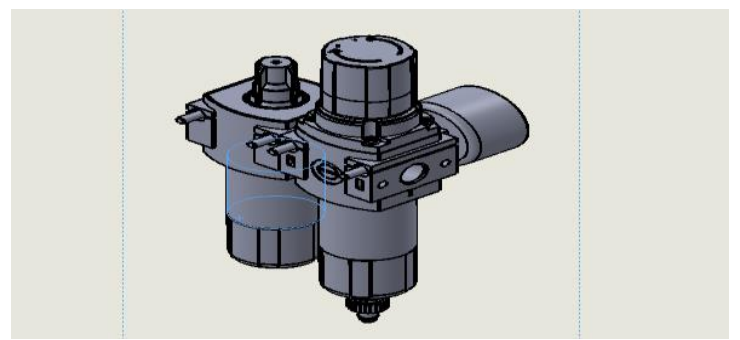

iv) Toggle Switch

Fig.8. FRL Unit

It is used for controlling and allowing the air flow through the ports of the double acting cylinder. When the toggle switch is pressed initially, air flows through the port near the bottom dead centre of the cylinder. When the piston is actuated at the bottom dead centre the pressed switch is reset automatically.

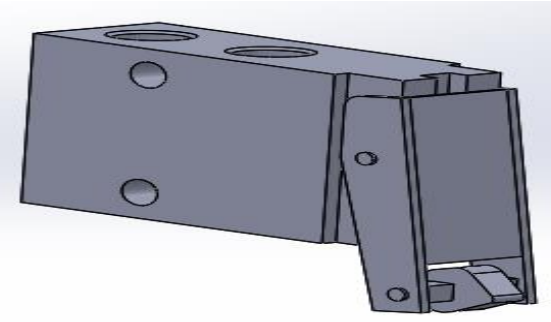

Fig.9. Toggle Switch

Sub-assemblies

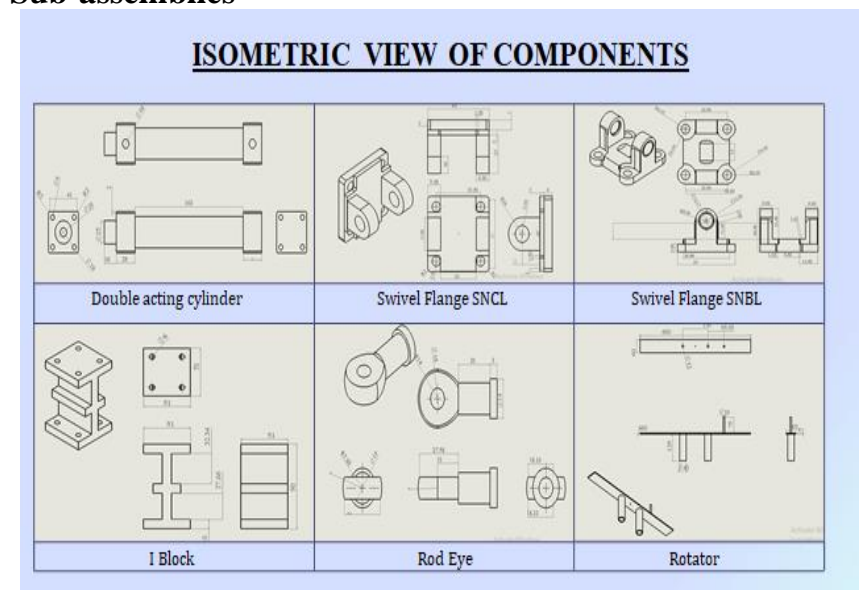

Fig.10. Sub-assemblies i) Rotator

It is used for rotating the flapper valve over the ram cylinder cover. It is linked in between flapper valve and the oscillating cylinder.

ii) Eye rod

It acts as a joint between the rotator and the oscillating cylinder.

\section{iii) Movable flange}

It is used for giving oscillating movement to the cylinder. It is connected between a fixed flange and the oscillating cylinder.

\section{iv) Fixed flange}

It serves as a fixed support between the movable flange and

I-shaped structure.

v) I-shaped structure

It serves as a rigid support between the fixed flange and the fixture. It is used for filling the gap between the cylinder end cap and the fixture.

\section{G. Materials used for assemblies and sub-assemblies}

TABLE IV. MATERIALS USED FOR ASSEMBLIES AND SUBASSEMBLIES

\begin{tabular}{|l|l|l|}
\hline S.NO & $\begin{array}{l}\text { ASSEMBLIES AND } \\
\text { SUB-ASSEMBLIES }\end{array}$ & MATERIALS \\
\hline 1. & Fixture & Sheet Metal \\
\hline 2. & Rotator & Mild Steel \\
\hline 3. & Eye Rod & Carbon Steel \\
\hline 4. & Movable Flange & Carbon Steel \\
\hline 5. & Fixed Flange & Carbon Steel \\
\hline 6. & I-Shaped Structure & Mild Steel \\
\hline 7. & $\begin{array}{l}\text { Pneumatic Cylinder And } \\
\text { Piston }\end{array}$ & $\begin{array}{l}\text { Aluminium And High } \\
\text { Alloy Steel }\end{array}$ \\
\hline 8. & FRL Unit & Poly Carbonate \\
\hline 9. & $\begin{array}{l}\text { Toggle valves, 5/2 } \\
\text { pneumatic double pilot } \\
\text { valve }\end{array}$ & Poly Carbonate \\
\hline 10 & Flapper Valve & 42FeCr16Mo \\
\hline
\end{tabular}

\section{H. Stepwise procedure for component assembly}

i) I-shaped structure was fixed to the fixture

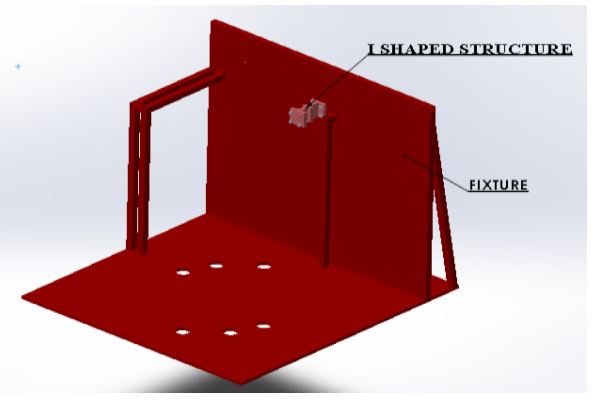

Fig.11. Step 1 
ii) Fixed flange assembly was mated with the I-shaped structure.

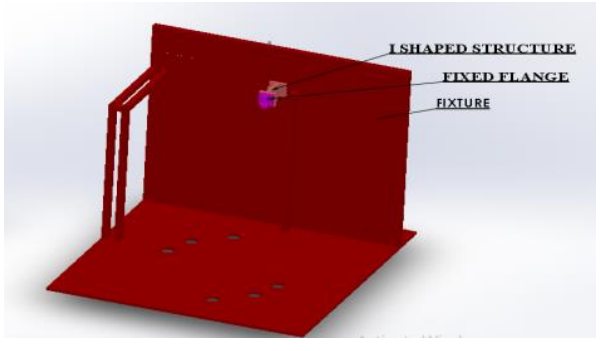

Fig.12. Step 2

iii) Movable flange assembly was mated with the fixed flange assembly.

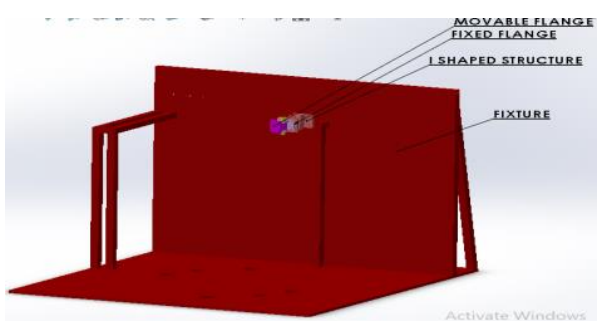

Fig.13. Step 3

iv) Pneumatic cylinder was mated with the movable flange.

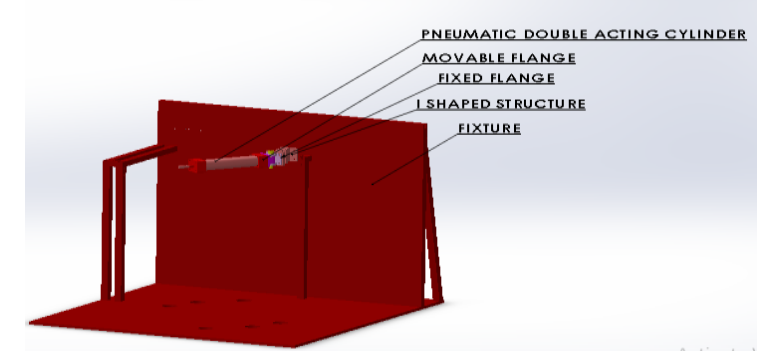

Fig.14.Step 4

v) Eye rod was mated with the piston end.

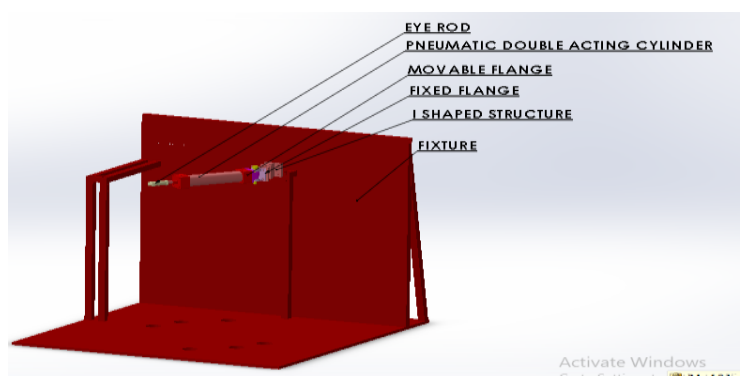

Fig.15. Step 5

vi) Suction Flange Cover assembly was fixed to the fixture, by using a mandrel.

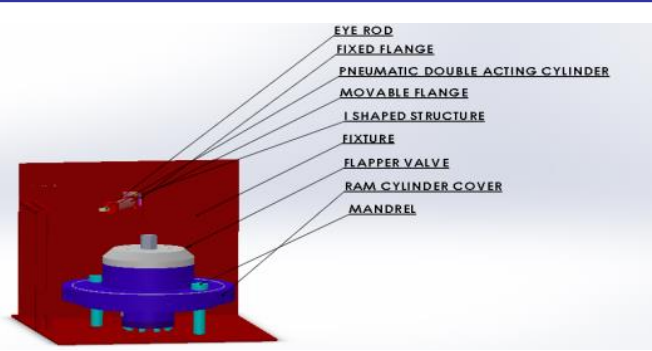

Fig.16. Step 6

vii) Rotator was fixed with the flapper valve. Mating was done between the projection from the rotator and the eye rod.

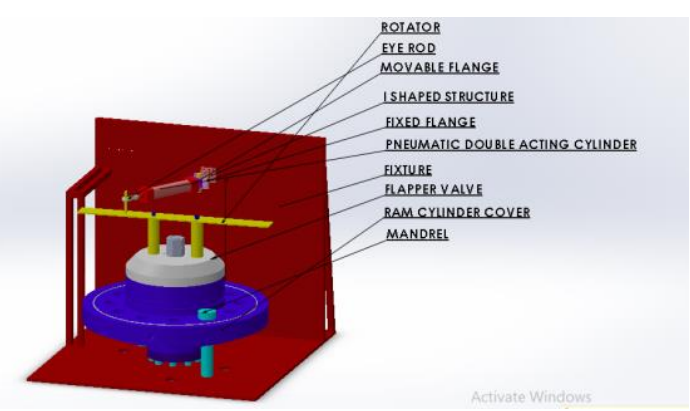

Fig.17. Step 7

viii) Pneumatic valves such as Toggle valves, $5 / 2$ double pilot valve and FRL unit are fixed to the fixture

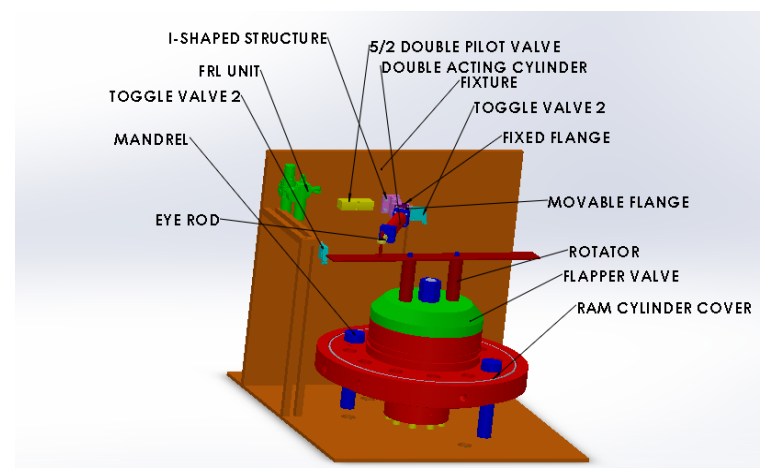

Fig.18. Step 8

\section{RESULT}

All the components were assembled on the designed fixture as mentioned in the assembly steps. The assembled mechanism of the pneumatic automated lapping system was simulated in the solid works software and the simulation and theoretical results were compared.

\section{A. Comparison of theoretical calculation with simulation result}

When piston is at bottom dead centre, cylinder is hinged to 57 degrees to the rotator. When the piston is at top dead centre the cylinder is hinged at 90 degrees to the rotator. 


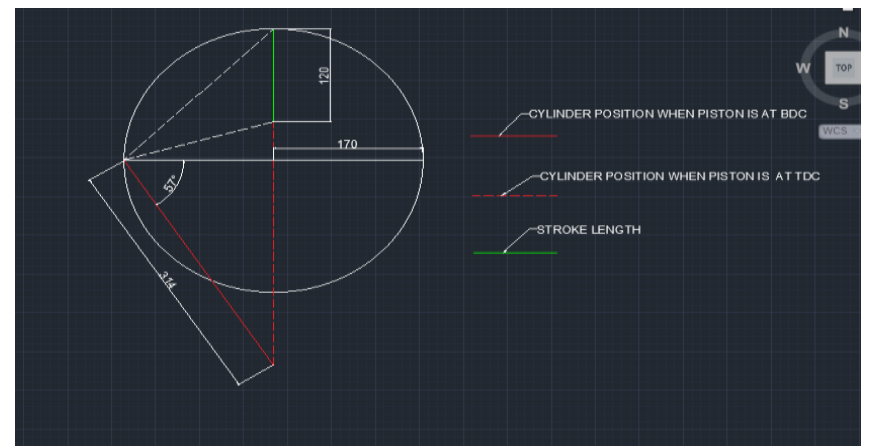

Fig.19. Theoretical calculation

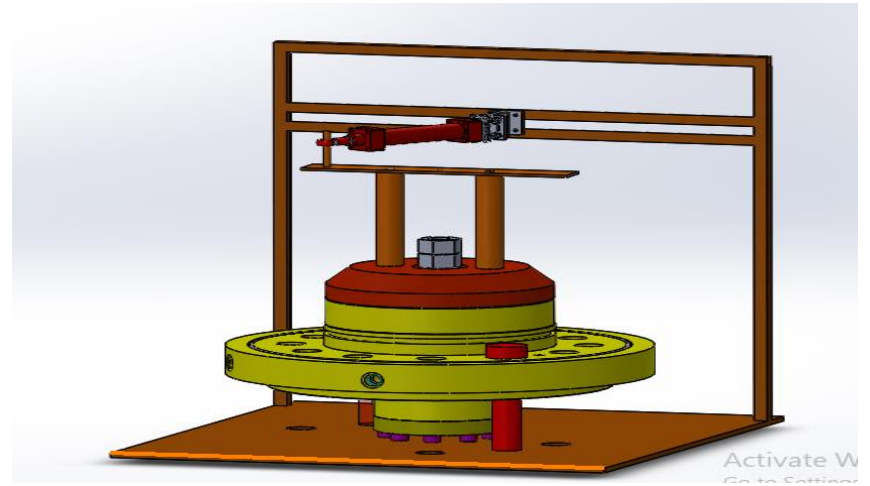

Fig.20.(a). Simulation analysis

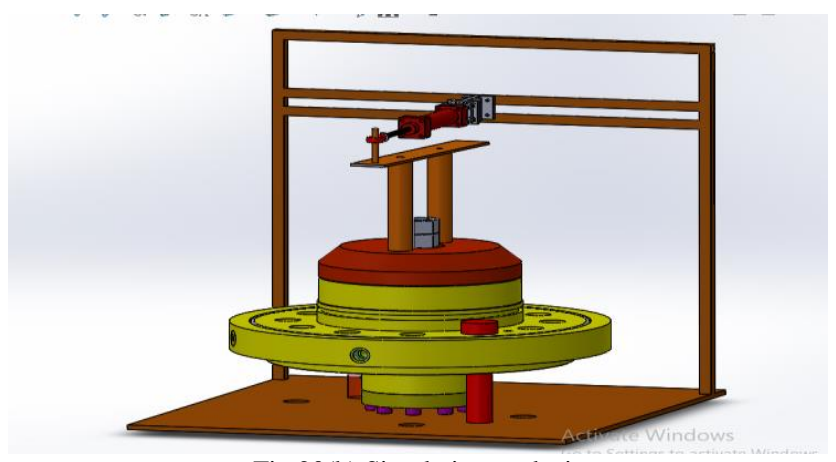

Fig.20(b) Simulation analysis

Inference: Flapper Valve (red coloured portion) rotates to 90 degrees along with the rotator which is connected to flapper valve and cylinder. Hence the theoretical calculation in fig 3.1 matches with the simulation analysis in fig 20(a) and fig $20(b)$.

\section{CONCLUSION}

A. Analysis from the motion study

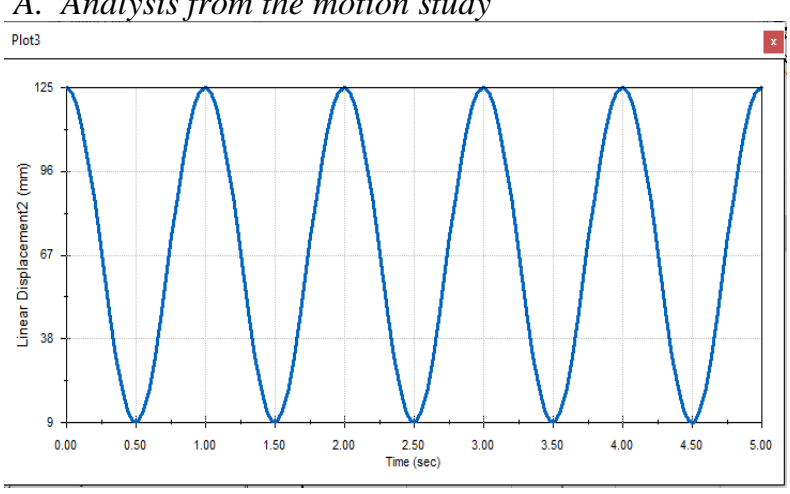

Fig.21. Displacement-time graph for piston movement
A displacement-time graph for the piston movement was generated from the motion study which was done on the designed model using solid works software. This graph explains about the reciprocating motion of the piston inside the cylinder at a stroke length of $125 \mathrm{~mm}$. It takes about 5 seconds to complete 5 strokes.

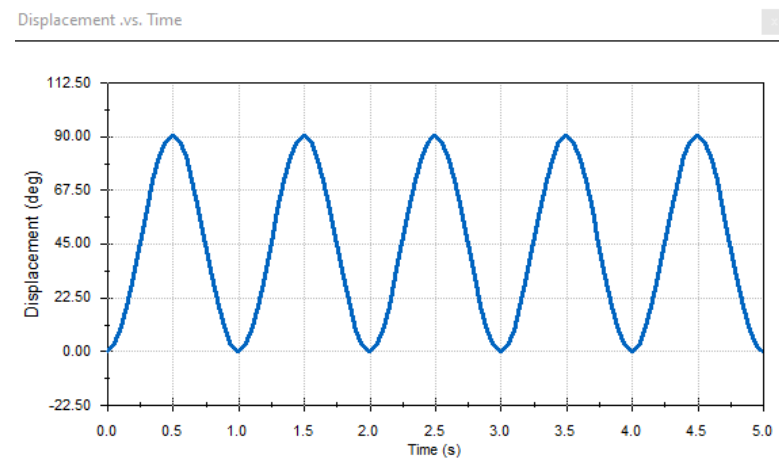

Fig.22. Displacement-time graph for flapper valve rotation

A displacement-time graph for the flapper valve rotation was generated from the motion study which was done on the designed model using the solid works software. The graph explains the oscillation of flapper valve which was restricted to 90 degrees for the stroke length of $125 \mathrm{~mm}$.

\section{Inference:}

Time taken for 1 rotation of flapper valve ( 0 to 90 degrees) is 0.5 seconds

Time taken for 200 rotations of the flapper valve is 100 seconds.

\section{B. Benefits of this methodology}

i. It eliminates human work load.

ii. It improves the efficacy of the lapping system. It takes about 100 seconds to complete the lapping process for one suction flange cover assembly

iii. Automation with toggle switches replaces the use of solenoids

iv. Circuit design is not complex.

v. System design is compact.

vi. Air flow can be controlled using the FRL unit.

\section{Shortcomings of this methodology}

i. Automation would stop if the rotator does not strike the toggle switch properly.

ii. Improper fixing of suction flange cover assembly would lead to decrease in efficacy of the system.

\section{Future scope of the system}

i. This system can be used for the lapping of other air tight assemblies, by changing the stroke length of the cylinder.

ii. Based on the application the mechanically actuating switches can be modified such as push button switches, lever switches. 


\section{ACKNOWLEDGMENT}

With a deep sense of gratitude we thank the God Almighty for giving us the strength and courage during the project work. We are also grateful to the faculty of the Department Of Mechanical Engineering of the Loyola Icam College of Engineering And Technology.

\section{REFERENCES}

[1] Design for automation:Rapid fixture approach

Author : R. Forestmann,J.Wagner,k.Kreiskother,a.kampker,D.Buschs.

[2] Manan Deb, Dibaker Sen "Design Of Double Toggle Switching Mechanism"(URL:www.elsevier.com/locate/mechant)

[3] Dominic S. Guevaara, Akira Kyusojin, Hiromi Isobe, Yoshiaki Kaneko,"Development of a new lapping method for high precision ball screw".

[4] Lalitnsuhas Deshpande,Shivakumar Raman,Owat Sunanta,Casmir Agbaraji,"observations in flat lapping of stainless steel and bronze"

[5] E. Uhlmann, T. Ardelt "Influence of Kinematics on the Face Grinding Process on Lapping Machines “ 